\title{
Long non-coding RNA HOTAIR is a marker for hepatocellular carcinoma progression and tumor recurrence
}

\author{
JIAN-ZHI GAO ${ }^{1,2^{*}}$, JIA LI ${ }^{2,3^{*}}$, JING-LI DU ${ }^{2}$ and XIAO-LEI LI ${ }^{4}$ \\ ${ }^{1}$ Department of Basic Medical Sciences, Xinxiang Medical College, Xinxiang, Henan 453003; ${ }^{2}$ Department of Pathology, \\ Chinese People's Liberation Army General Hospital, Beijing 100853; ${ }^{3}$ Department of Pathology, \\ Beijing Tiantan Hospital Affiliated to Capital University of Medical Sciences, Beijing 100050; \\ ${ }^{4}$ Department of Molecular Biology, Institute of Basic Medicine, Chinese People's Liberation Army General Hospital, \\ Beijing 100853, P.R. China
}

Received November 2, 2014; Accepted August 25, 2015

DOI: $10.3892 / 01.2016 .4130$

\begin{abstract}
The present study aimed to investigate the expression level of HOX transcript antisense RNA (HOTAIR) in hepatocellular carcinoma (HCC) and its association with various clinicopathological characteristics, and to further explore the molecular mechanisms of HOTAIR function in HCC. Quantitative reverse transcription-polymerase chain reaction (RT-PCR) was used to detect the expression level of HOTAIR in 60 paired fresh HCC samples and adjacent normal liver tissue samples. The association between HOTAIR expression and clinicopathological parameters was analyzed. Lentivirus-mediated HOTAIR-specific small hairpin RNA vectors were transfected into HepG2 cells. Cell proliferation and invasion in vitro were examined by MTT and Transwell assays, respectively. A xenograft model was used to analyze the tumorigenesis of liver cancer cells in vivo. In addition, semi-quantitative RT-PCR was used to detect the expression level of Wnt/ $\beta$-catenin signaling molecules under the condition of HOTAIR inhibition. The results revealed that the expression level of HOTAIR in HCC tissues was higher than that in adjacent non-cancerous tissues. HOTAIR expression was significantly associated with poor tumor differentiation $(\mathrm{P}=0.002)$, metastasis $(\mathrm{P}=0.002)$ and early recurrence $(\mathrm{P}=0.001)$. In vitro, the inhibition of HOTAIR in liver cancer cells resulted in the suppression of cell proliferation and invasion. HOTAIR depletion significantly inhibited the rate of growth of liver cancer cells in vivo. Furthermore, the expression levels of Wnt and $\beta$-catenin were downregulated when HOTAIR expression was suppressed. In conclusion, HOTAIR is important in the progression and recurrence of $\mathrm{HCC}$, partly through the
\end{abstract}

Correspondence to: Professor Jian-Zhi Gao, Department of Basic Medical Sciences, Xinxiang Medical College, 601 Jinsui Road, Xinxiang, Henan 453003, P.R. China

E-mail: gaoteng.bao@163.com

${ }^{*}$ Contributed equally

Key words: long non-coding RNA, HOX transcript antisense RNA, hepatocellular carcinoma, progression, recurrence regulation of the Wnt/ $\beta$-catenin signaling pathway. Targeting HOTAIR may be a novel therapeutic strategy for HCC.

\section{Introduction}

Hepatocellular carcinoma (HCC) is the fifth most frequent cancer worldwide and is also the third leading cause of cancer-related mortality (1). The World Health Organization has estimated that almost 56,400 new cases of HCC occur globally per year (2), and the incidence is markedly higher in men than in women. The highest liver cancer rates are observed in developing countries, particularly in East Asia and Malaysia, South Africa and Sub-Saharan Africa, whereas rates are lower in Europe, North and South America, Australia and New Zealand (3). HCC may be induced by a number of risk factors, including chronic infection with hepatitis $\mathrm{B}$ virus (HBV) or hepatitis $\mathrm{C}$ virus (HCV), hepatic cirrhosis, alcoholic liver disease and exposure to aflatoxins (4).

Despite recent advances in surgical treatments and chemoradiotherapy, aggressive metastasis and early recurrence still result in a high mortality rate among $\mathrm{HCC}$ patients (5). To date, a number of molecular markers and signaling pathways have been identified to be associated with HCC oncogenesis, progression, recurrence and survival, including tumor protein P53 (TP53), K-ras mutation (6,7), HBx, Notch 1, Glypican-3 and osteopontin overexpression (7-10), Wnt/ $\beta$-catenin and the phosphoinositide 3-kinase/protein kinase $\mathrm{B} /$ mammalian target of rapamycin signaling pathways $(11,12)$. However, the exact mechanism of $\mathrm{HCC}$ has not been fully established. Therefore, a better understanding of the molecular mechanisms underlying HCC may contribute to the development of novel strategies for prediction, diagnosis and therapy.

Long non-coding RNAs (lncRNAs) are non-protein-coding transcripts of $>200$ nucleotides (13). A recent study found that the human genome consists of at least four times more lncRNA sequences than coding RNA sequences (14). The majority of lncRNAs demonstrated to be functional are involved in the regulation of gene transcription, post-transcriptional regulation and epigenetic regulation, such as genomic imprinting and $\mathrm{X}$-inactivation (15-17), and are closely associated with numerous human diseases, including cancer $(18,19)$. The lncRNA HOX transcript 
antisense RNA (HOTAIR), a human gene located on chromosome 12, is expressed from the HOXC locus and is important in the transcriptional regulation of various genes (20). The 5' end of HOTAIR interacts with and induces the genome-wide retargeting of Polycomb Repressive Complex 2 (PRC2), which combines with HOTAIR to silence the transcription of the HOXC locus, and promotes metastasis of breast cancer by silencing multiple metastasis suppressor genes (21). The 3' end of HOTAIR interacts with lysine-specific histone demethylase 1A (22). Furthermore, recent studies have reported that HOTAIR is highly expressed and associated with poor prognosis in a number of types of cancer, including breast cancer, epithelial ovarian cancer, pancreatic cancer, colorectal cancer, non-small-cell lung cancer and endometrial carcinoma (21,23-27).

The objective of the current study was to investigate the expression of HOTAIR in HCC and to further explore its clinical significance and molecular mechanisms. Paired fresh HCC samples and adjacent normal tissues were used to examine the expression level of HOTAIR and analyze the association between HOTAIR expression and clinicopathological characteristics. Furthermore, a lentivirus-mediated RNA interference method was utilized to investigate the role and molecular mechanism of HOTAIR in HCC progression.

\section{Materials and methods}

Patients and tissue samples. The patients enrolled in the study were diagnosed with primary HCC and underwent partial liver resection between January and September 2012 at Chinese People's Liberation Army (PLA) General Hospital (Beijing, China). A total of 60 paired samples of HCC and non-cancerous tissue were obtained from the resected tumors and adjacent normal liver tissues of the patients, and were immediately frozen in liquid nitrogen and stored at $-80^{\circ} \mathrm{C}$ until use. This study was approved by the ethics committee of Chinese PLA General Hospital (LREC 2012/40) and the protocol was conducted with the prior written informed consent of all patients. All samples were confirmed independently by two pathologists, and the clinicopathological characteristics were documented and are described in detail in Table I.

RNA extraction, reverse transcription $(R T)$ and quantitative $(q)$ polymerase chain reaction $(P C R)$. Total RNA from frozen HCC and paired non-cancerous tissues or cell lines were extracted with the Ultrapure RNA Kit (CWBio, Co., Ltd., Beijing, China) according to the manufacturer's instructions. cDNA was synthesized by reverse transcribing the total RNA using a HiFi-MMLV cDNA Kit (CWBio, Co., Ltd.). The expression level of HOTAIR was detected by qPCR using the Ultra SYBR Mixture with ROX (CWBio, Co., Ltd.) and ABI7500 system (Applied Biosystems Life Technologies, Foster City, CA, USA). Template cDNA $(2 \mu \mathrm{l})$ was mixed with $25 \mu 12 \mathrm{X}$ UltraSYBR Mixture with ROX, $2 \mu \mathrm{l}$ primers and RNase-free water. $\beta$-actin was used as an internal control and HOTAIR values were normalized to $\beta$-actin. The primer sequences (Invitrogen; Thermo Fisher Scientific, Waltham, MA, USA) used were as follows: HOTAIR forward, 5'-GCA GTAGAAAAATAGACATAGGAGA-3', and reverse, 5'-ATA GCAGGAGGAAGTTCAGGCATTG-3'; $\beta$-actin forward, 5'-ACTTAGTTGCGTTACACCCTT-3', and reverse, 5'-GTC
ACCTTCACCGTTCCA-3'. HOTAIR cDNA was amplified under the following conditions: Initital denaturation at $95^{\circ} \mathrm{C}$ for 5 min followed by 30 cycles of denaturation at $95^{\circ} \mathrm{C}$ for $30 \mathrm{sec}$ and primer annealing at $55^{\circ} \mathrm{C}$ for $30 \mathrm{sec}$, with a final extension step at $72^{\circ} \mathrm{C}$ for $60 \mathrm{sec}$. Expression levels were calculated using the $2^{-\Delta \Delta \mathrm{CT}}$ method (28) and were normalized to that of the housekeeping $\beta$-actin gene.

HOTAIR siRNA lentiviral expression vector. The RNA interference sequence for human HOTAIR (Gene ID, 100124700) was obtained from a previous article (21). The small interfering RNA (siRNA) sequences were as follows: HOTAIR, 5'-UAACAA GACCAGAGAGCUGUU-3'; negative control (NC), 5'-TTC TCCGAACGTGTCACGT-3'. The oligonucleotides encoding short hairpin RNA (shRNA) were then constructed and synthesized by Shanghai GenePharma Co., Ltd. (Shanghai, China) and annealed into double strands by Annealing Buffer for RNA Oligos (Beyotime Institute of Biotechnology, Haimen, China). Following digestion with BamHI and EcoRI restriction endonucleases (TransGen Biotech, Inc., Beijing, China), the double stranded DNA molecules were inserted into pGCSi-neo-GFP lentiviral vector (lentiviral plasmid and packaging vectors were provided by Dr Xiao-Lei Li from the Department of Molecular Biology of Chinese PLA General Hospital). All of the constructed plasmids were confirmed by DNA sequencing. pGCSi-neo-GFP-HOTAIR-shRNA/NC-shRNA plasmid DNAs, along with packaging vectors, were transiently transfected into HEK293T (American Type Culture Collection, Manassas, VA, USA) cells using Lipofectamine 2000 (Invitrogen; Thermo Fisher Scientific) according to the manufacturer's instructions. At $48 \mathrm{~h}$ after transfection, supernatants containing lentivirus were collected and purified by ultracentrifugation at $70,000 \mathrm{x}$ a at $4^{\circ} \mathrm{C}$ for $2 \mathrm{~h}$. The titer of the lentivirus was detected using Lentivirus-Associated HIV p24 ELISA Kit (Cell Biolabs, Inc., San Diego, CA, USA).

Cell culture and lentiviral infection. Human liver cancer HepG2 cells were purchased from the American Type Culture Collection and maintained in the research center from the Department of Gastroenterology in Chinese PLA General Hospital. Cells were maintained in Dulbecco's modified Eagle's medium (DMEM; Gibco; Thermo Fisher Scientific) supplemented with $10 \%$ fetal bovine serum (FBS; Gibco; Thermo Fisher Scientific) and penicillin-streptomycin (MP Biomedicals, Santa Ana, CA, USA) at $37^{\circ} \mathrm{C}$ in an atmosphere of $5 \% \mathrm{CO}_{2}$. For transfection, well-cultured cells were seeded into a 6 -well plate at a density of $1 \times 10^{5}$ cells/well for $24 \mathrm{~h}$. Subsequently, lentivirus containing shRNA targeting HOTAIR or NC shRNA was added into the medium and incubated for $24 \mathrm{~h}$. After replacing the culture medium of each well, cells were incubated for a further $48 \mathrm{~h}$. qPCR was performed to detect the interference efficiency of the HOTAIR shRNA.

MTT assay. For cell proliferation assays, HepG2 cells stably transfected with HOTAIR shRNA or NC shRNA were digested with $0.25 \%$ trypsin (Boster Inc., Wuhan, China), seeded into 96-well plates at a density of 1,000 cells/well in a final volume of $100 \mu \mathrm{l}$, and maintained in DMEM supplemented with $10 \%$ FBS. At different time points $(24$ h, 48 h, 72 h, 4 days, 5 days, 6 days or 7 days after plating), $10 \mu$ MTT solution 
Table I. Association between HOTAIR expression and clinicopathological parameters in hepatocellular carcinoma patients ( $\mathrm{n}=60$ ).

\begin{tabular}{|c|c|c|c|c|c|}
\hline \multirow[b]{2}{*}{ Characteristic } & \multirow[b]{2}{*}{$\mathrm{n}$} & \multicolumn{2}{|c|}{ HOTAIR expression, $\mathrm{n}$} & \multirow[b]{2}{*}{$\chi^{2}$} & \multirow[b]{2}{*}{ P-value } \\
\hline & & High $(\mathrm{n}=36)$ & Low $(n=24)$ & & \\
\hline Gender & & & & 0.082 & 0.775 \\
\hline Male & 42 & 25 & 17 & & \\
\hline Female & 18 & 10 & 8 & & \\
\hline Age (years) & & & & 0.866 & 0.352 \\
\hline$<50$ & 22 & 10 & 12 & & \\
\hline$\geq 50$ & 38 & 22 & 16 & & \\
\hline Tumor size (cm) & & & & 0.431 & 0.512 \\
\hline$\leq 5$ & 22 & 12 & 10 & & \\
\hline$>5$ & 38 & 24 & 14 & & \\
\hline Tumor number & & & & 3.386 & 0.066 \\
\hline Solitary & 42 & 22 & 20 & & \\
\hline Multiple & 18 & 14 & 4 & & \\
\hline Serum $\alpha$-fetoprotein $(\mu \mathrm{g} / \mathrm{l})$ & & & & 2.188 & 0.139 \\
\hline$<400$ & 32 & 22 & 10 & & \\
\hline$\geq 400$ & 28 & 14 & 14 & & \\
\hline Peritumoral tissue & & & & 3.103 & 0.078 \\
\hline Non-cirrhotic & 2 & 0 & 2 & & \\
\hline Cirrhotic & 58 & 36 & 22 & & \\
\hline Tumor differentiation & & & & 12.198 & $0.002^{\mathrm{a}}$ \\
\hline Well & 6 & 0 & 6 & & \\
\hline Moderate & 28 & 16 & 12 & & \\
\hline Poor & 26 & 20 & 6 & & \\
\hline TNM stage & & & & 6.389 & 0.094 \\
\hline I & 12 & 4 & 8 & & \\
\hline II & 6 & 4 & 2 & & \\
\hline III & 30 & 18 & 12 & & \\
\hline IV & 12 & 10 & 2 & & \\
\hline Vessel embolus & & & & 3.403 & 0.065 \\
\hline Negative & 48 & 26 & 22 & & \\
\hline Positive & 12 & 10 & 2 & & \\
\hline Metastasis & & & & 10.000 & $0.002^{\mathrm{a}}$ \\
\hline Negative & 48 & 24 & 24 & & \\
\hline Positive & 12 & 12 & 0 & & \\
\hline Early recurrence ( $<2$ years) & & & & 11.250 & $0.001^{\mathrm{a}}$ \\
\hline Negative & 40 & 18 & 22 & & \\
\hline Positive & 20 & 18 & 2 & & \\
\hline
\end{tabular}

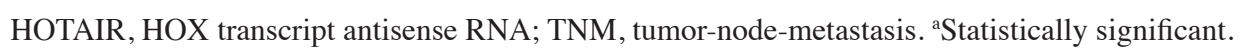

(Sigma-Aldrich, St. Louis, MO, USA) was added to each well, and cells were incubated for an additional $4 \mathrm{~h}$ at $37^{\circ} \mathrm{C}$. The blue formazan crystals were dissolved in $100 \mu \mathrm{l}$ dimethyl sulfoxide (Origen Bioedical, Austin, TX, USA), and the absorbance was measured at $490 \mathrm{~nm}$ using a microplate reader (ELx800; BioTek Instuments, Inc., Winooski, VT, USA).

Transwell assay. A Transwell assay was performed to assess the invasiveness of HepG2 cells by using chambers with an
$8.0 \mu \mathrm{m}$ transparent polyethylene terephthalate membrane in 24-well plates (Corning Incorporated, Corning, New York, NY, USA). Cells $\left(2 \times 10^{5}\right.$ per chamber $)$ were seeded into the upper chambers in $200 \mu \mathrm{l}$ serum-free DMEM, and $500 \mu \mathrm{l}$ of DMEM with $10 \%$ FBS was added to each lower chamber. Three duplicate wells were performed for each group. After $12 \mathrm{~h}$, the unfiltered cells at the top surface of the membrane were gently removed with cotton swabs. The cells that had passed through the filters were fixed in methanol for $15 \mathrm{~min}$ 
and stained with hematoxylin (OriGene China, Beijing, China) for $20 \mathrm{~min}$, air-dried and photographed (Olympus Stream Image Analysis Software; Olympus Corporation, Tokyo, Japan). The invasive cells were counted under a microscope (magnification, x200; CX31; Olympus Corporation) in five randomly selected visual fields.

Xenograft model. To examine the ability of tumor formation in vivo, the cell lines stably transfected with HOTAIR shRNA or NC shRNA were injected into nude mice. Ten four-week-old $\mathrm{BALB} / \mathrm{c}$ male nude mice were purchased from the Vital River Laboratories (Beijing, China) and randomly assigned to two groups. All nude mice were bred and maintained at the the Vital River Laboratories (Beijing, China) under specific pathogen-free conditions. The research program, objective and animal use protocol were reviewed and approved by the Animal Ethical and Welfare Committee of Tsinghua University. Cell suspension $(100 \mu \mathrm{l})$ containing 1x10 ${ }^{7}$ HepG2-HOTAIR-shRNA or HepG2-NC-shRNA cells was injected subcutaneously into the back of each nude mouse. The tumor size and weight of the mice were measured every 4 days from the 8th day following injection. On the 28th day following injection, all mice in the two groups were sacrificed by cervical dislocation and the primary tumors were removed from each mouse. Tumor size and tumor weight were measured and recorded. The tumor volume was calculated according to the following formula: Tumor volume $=$ length $\mathrm{x}$ width ${ }^{2} \mathrm{x} \pi / 6$ (29).

Semi-quantitative RT-PCR. Semi-quantitative RT-PCR was performed to assess the mRNA expression levels of Wnt and $\beta$-catenin in tumor tissues from nude mice. The methods for RNA extraction and RT were performed using the aforementioned method. 2X Taq MasterMix (CWBio, Co., Ltd.) was used to amplify the cDNA. The PCR cycling parameters (30 cycles) were as follows: Predenaturation $\left(95^{\circ} \mathrm{C}, 5 \mathrm{~min}\right)$, denaturation $\left(95^{\circ} \mathrm{C}, 30 \mathrm{sec}\right)$, annealing $\left(55^{\circ} \mathrm{C}, 30 \mathrm{sec}\right)$ and extension $\left(72^{\circ} \mathrm{C}\right.$, $60 \mathrm{sec})$. GAPDH was used as an internal control. The RNA primers (Invitrogen; Thermo Fisher Scientific) used in the PCR were as follows: Wnt forward, 5'-GGAGTTGTATTTGCCATC ACCAGGG-3', and reverse, 5'-ATGCGCGGGCAAATTTGA TCCCATA-3'; $\beta$-catenin forward, 5'-ACAAGCCACAAGATT ACAAGAAACGG-3', and reverse, 5'-CCACCAGAGTGA AAAGAACGATAGCT-3'; GAPDH forward, 5'-TGGAGTCTA CTGGCGTCTT-3', and reverse, 5'-TGTCATATTTCTCGT GGTTCA-3'. The PCR products were assessed by $1.5 \%$ agarose gel electrophoresis. Expression levels were calculated using the $2^{-\triangle \Delta C T}$ method (28) and were normalized to that of the housekeeping $\beta$-actin gene

Statistical analysis. All statistical analyses were performed using SPSS version 20.0 statistical software package (IBM SPSS, Armonk, NY, USA) or GraphPad Prism version 5.0 (GraphPad Software, Inc., La Jolla, CA, USA). A $\chi^{2}$ test was used to assess the association between HOTAIR expression level or tumor recurrence and clinicopathological characteristics. Comparisons of quantitative data between two groups were analyzed by an independent-samples $t$-test. Spearman's correlation test was used to analyze the correlation between HOTAIR expression level and clinicopathological factors. All experiments were repeated independently three times and data
Table II. Spearman rank correlation coefficient analysis between HOTAIR expression level and clinicopathological factors.

\begin{tabular}{lcc}
\hline & \multicolumn{2}{c}{ Relative HOTAIR expression } \\
\cline { 2 - 3 } Characteristic & Correlation coefficient & P-value \\
\hline Tumor size $(\mathrm{cm})$ & 0.085 & 0.520 \\
Tumor number & 0.238 & 0.068 \\
Serum $\alpha$-fetoprotein $(\mu \mathrm{g} / \mathrm{l})$ & -0.191 & 0.144 \\
Peritumoral tissue cirrhosis & 0.227 & 0.081 \\
Tumor differentiation & 0.391 & $0.002^{\mathrm{a}}$ \\
TNM stage & 0.293 & $0.023^{\mathrm{a}}$ \\
Vessel embolus & 0.238 & 0.067 \\
Metastasis & 0.408 & $0.001^{\mathrm{a}}$ \\
Early recurrence $(<2$ years $)$ & 0.433 & $0.001^{\mathrm{a}}$ \\
\hline
\end{tabular}

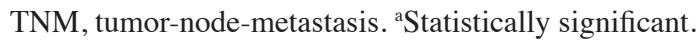

are presented as the mean \pm standard deviation. $\mathrm{P}<0.05$ was considered to indicate statistical significance.

\section{Results}

Increased expression of HOTAIR in HCC. To examine the expression level of the IncRNA HOTAIR in HCC and its association with clinical progression of HCC, HOTAIR expression was detected in 60 paired fresh HCC tissues and adjacent non-cancerous tissues using qPCR. The results revealed that HOTAIR expression was increased at least 2-fold relative to that in non-cancerous samples in 36 (60\%) HCC samples; the mean expression level of HOTAIR in HCC samples was 5.7-fold higher than the mean level in the adjacent non-cancerous tissue samples $(\mathrm{P}=0.014, t$-test; Fig. $1 \mathrm{~A})$.

Correlation between HOTAIR expression and clinicopathological parameters of HCC. The association between HOTAIR expression and the clinicopathological characteristics of patients with HCC was assessed (Table I). Significant associations were identified between the HOTAIR expression and a number of clinicopathological parameters that represent higher tumor burdens, including poor tumor differentiation $(\mathrm{P}=0.002)$, metastasis $(\mathrm{P}=0.002)$ and early recurrence (within 2 years; $\mathrm{P}=0.001$ ). Statistical analyses revealed no association between HOTAIR expression and tumor size, tumor number, serum $\alpha$-fetoprotein level, cirrhosis, tumor-node-metastasis (TNM) stage (30) or the presence of vessel emboli. Spearman's rank correlation coefficient analysis revealed that a high expression level of HOTAIR was strongly correlated with tumor differentiation $(\mathrm{r}=0.391$, $\mathrm{P}=0.002)$, TNM stage $(\mathrm{r}=0.293, \mathrm{P}=0.023)$, metastasis $(\mathrm{r}=0.408$, $\mathrm{P}=0.001)$ and early recurrence $(\mathrm{r}=0.433, \mathrm{P}=0.001)$ (Table II). Taken together, these observations indicated that increased HOTAIR expression is associated with HCC progression and early recurrence.

Downregulation of HOTAIR inhibits proliferation of HepG2 cells. As the clinical data indicated that the expression level of HOTAIR was closely associated with human HCC progression, 
A

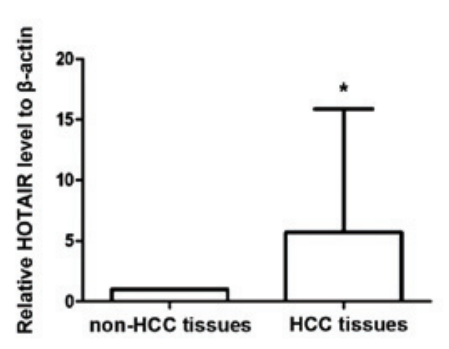

D

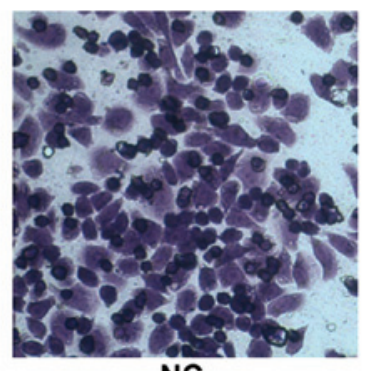

NC
B
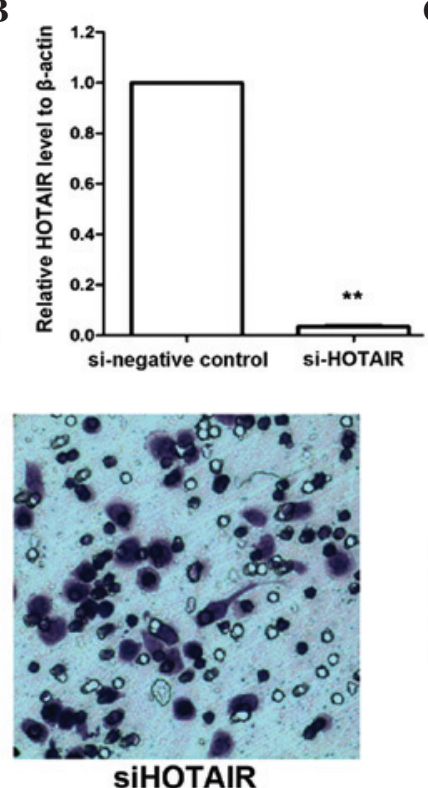

C
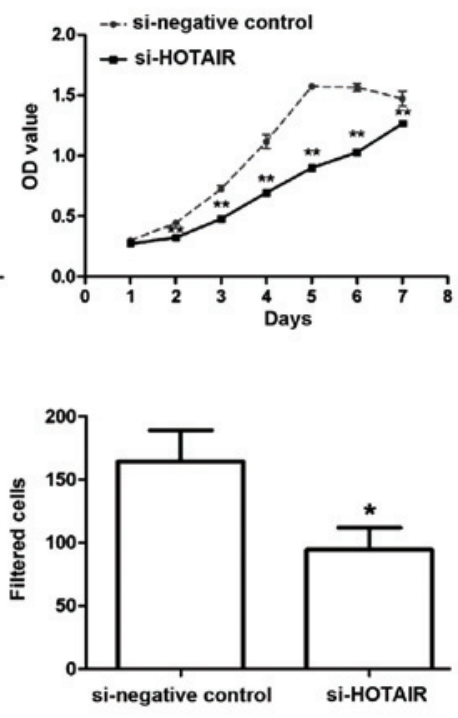

Figure 1. (A) Expression of HOTAIR in 60 paired HCC and adjacent non-HCC tissues detected by quantitative PCR. Bars represent mean \pm standard deviation; "P<0.05 vs. NC (Student's $t$-test). (B) Interference efficiency of HOTAIR in HepG2 cells. ${ }^{* *} \mathrm{P}<0.01$ vs. NC (Student's $t$-test). (C) Effect of HOTAIR silence on cell proliferation assessed my MTT assay. HepG2 cells treated with siHOTAIR exhibited a marked inhibition in cell growth compared with cell treated with siNC; ${ }^{* *} \mathrm{P}<0.01$ vs. NC (Student's $t$-test). (C) Transwell invasion assays were applied to assess for cell invasion ability, revealing that downregulation of HOTAIR inhibits invasion in HepG2 liver cancer cells (crystal violet staining; magnification, x200); bars represent mean \pm standard deviation; " $\mathrm{P}<0.05$ vs. NC (Student's $t$-test). HCC, hepatocellular carcinoma; HOTAIR, HOX transcript antisense RNA; OD, optical density; NC, negative control.

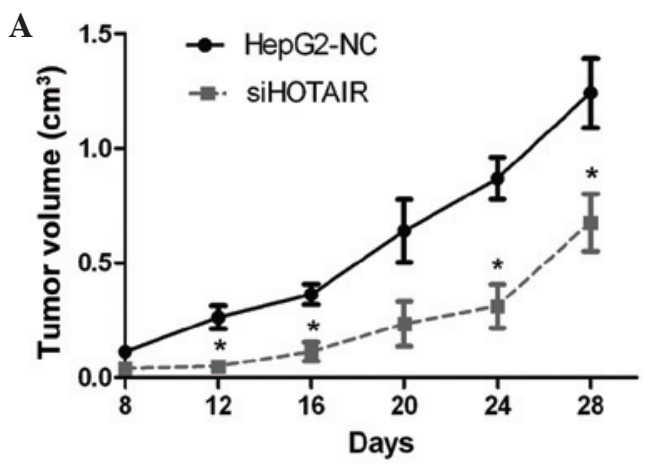

$\mathbf{C}$

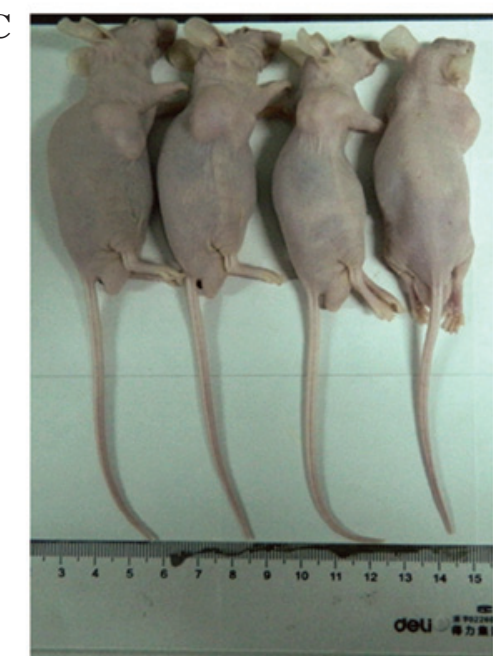

siNC
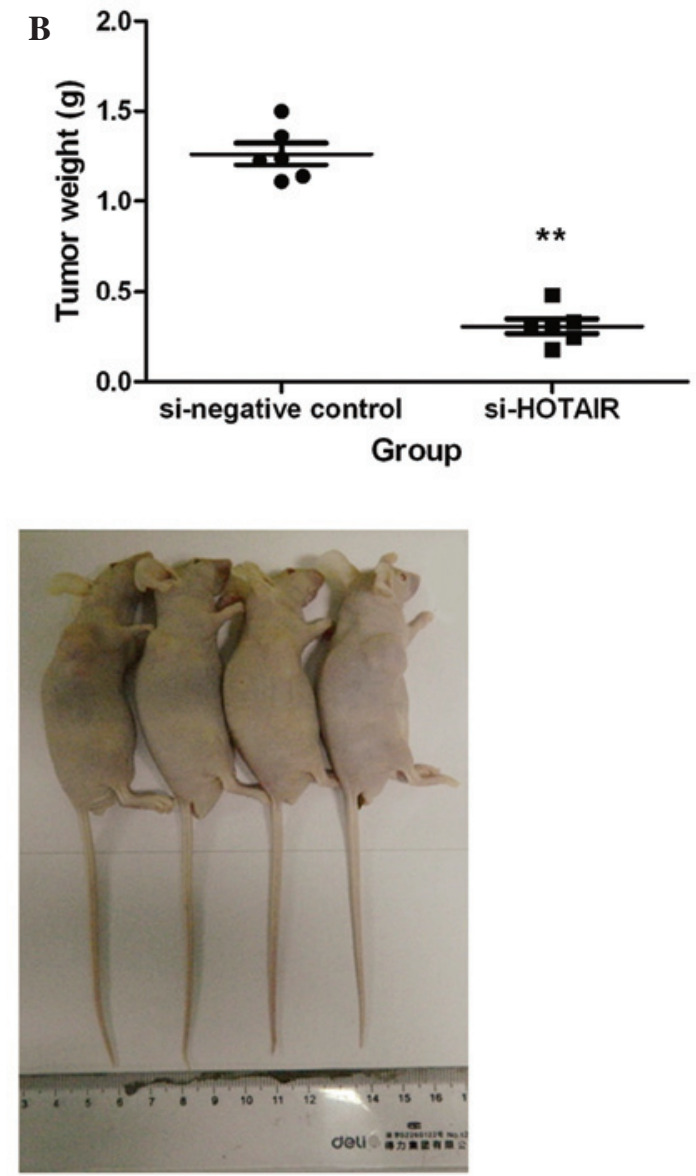

SiHOTAIR

Figure 2. Expression of HOTAIR regulates tumorigenicity of liver cancer cells in xenograft models. (A) Tumor growth curves in nude mice from two groups. Tumors in the siHOTAIR group grew markedly slower than siNC group ( $\mathrm{P}<0.05)$. (B) The mean tumor weights were markedly reduced in siHOTAIR group vs. siNC group $\left({ }^{* *} \mathrm{P}<0.01\right)$. (C) Four mice with primary tumors from each group were photographed prior to sacrifice. HOTAIR, HOX transcript antisense RNA; NC, negative control. 


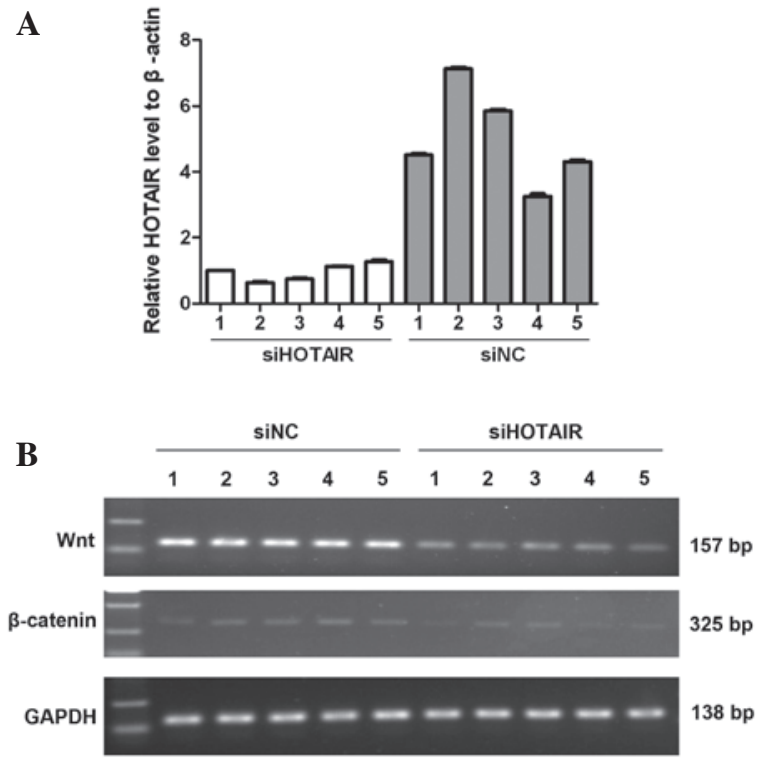

Figure 3. (A) Relative expression levels of HOTAIR in primary tumors from nude mice detected by quantitative PCR. (B) The expression level of Wnt and $\beta$-catenin were examined in primary tumors by semi-quantitative PCR. HOTAIR, HOX transcript antisense RNA; NC, negative control; PCR, polymerase chain reaction.

the effect of HOTAIR on the proliferation of liver cancer cells was investigated. The constructed lentiviral vectors designated siHOTAIR and siNC were transfected into HepG2 liver cancer cells, and the interference efficiency was detected by qPCR following transfection for $72 \mathrm{~h}$. As shown in Fig. 1B, the expression level of HOTAIR was significantly downregulated by $95 \%$ in siHOTAIR cells compared with NC cells $(\mathrm{P}<0.001)$.

An MTT assay was performed to examine the effect of HOTAIR on liver cancer cell proliferation. The results revealed that the cell proliferative ability of siHOTAIR stably transfected cells was markedly inhibited compared to the NC cells (Fig. 1C). These data indicate that HOTAIR is important in liver cancer cell proliferation in vitro.

Inhibition of HOTAIR reduces invasiveness of HepG2 cells. A Transwell assay was used to assess the effect of HOTAIR on the invasive ability of liver cancer cells. The results revealed that the number of cells that passed through the filters was significantly decreased in the siHOTAIR group compared with that of siNC group (Fig. 1D). Statistical analysis indicated that the difference between two groups was significant $(\mathrm{P}=0.049)$. This finding demonstrated that increased expression of HOTAIR may enhance liver cancer cell invasiveness in vitro.

HOTAIR expression regulates the tumorigenicity of HepG2 cells. To further determine whether HOTAIR expression could promote HCC progression and enhance the tumorigenicity of liver cancer cells, an in vivo tumor model was used. Using a shRNA lentiviral knockdown system, two stable cell lines, HepG2-siHOTAIR and HepG2-siNC, were generated and injected subcutaneously into the backs of nude mice $(n=5$ per group). Tumor volumes were measured every 4 days until the 28th day following injection. As shown in Fig. 2A, tumors from HepG2-siNC cells grew faster than tumors formed from siHOTAIR cells. In addition, the mean tumor weight in
HepG2-siHOTAIR group was significantly lower compared with that from the HepG2-siNC group (Fig. 2B). Four mice from each group were photographed and tumor size in the siHOTAIR group was observed to be markedly smaller than that in the NC group (Fig. 2C). These in vivo results were consistent with the findings of the in vitro experiments, and suggested that HOTAIR regulates liver cancer cell proliferation, invasion and the tumorigenic ability, and may play an important role in HCC progression.

HOTAIR regulates Wnt/ $\beta$-catenin mRNA expression. Tumor models of the nude mice from the two groups (5 per group) were used to detect the mRNA expression levels of Wnt and $\beta$-catenin under the condition of HOTAIR inhibition using semi-quantitative RT-PCR. The interference efficiency of HOTAIR in these tumor models was confirmed by qPCR (Fig. 3A). As shown in Fig. 3B, in the siHOTAIR group, the expression levels of $\mathrm{Wnt}$ and $\beta$-catenin were markedly reduced compared with those of the NC group. These data indicate that HOTAIR may regulate $\mathrm{Wnt} / \beta$-catenin expression alone or in combination with other molecules by an unknown mechanism that merits further study.

\section{Discussion}

HCC is a significant health problem worldwide, with high rates of incidence and mortality (2). Accumulative, long-term interactions between environmental and genetic factors lead to the occurrence and progression of HCC (31). Although a number of tumor suppressor genes and oncogenes, including KRAS, PTEN and TP53, have been identified to be involved in HCC progression $(6,7,32)$, the molecular mechanism of HCC is not completely understood. In recent years, the focus of tumor research has expanded to investigate the potential tumor suppressive or oncogenic functions of lncRNAs $(33,34)$.

HOTAIR is an oncogenic lncRNA that has been found to interact with PRC2 to epigenetically regulate chromatin state and multiple target genes (21). Recently, accumulating evidence has demonstrated that HOTAIR is dysregulated in various types of cancer. Gupta et al (21) reported that HOTAIR is highly expressed in metastatic breast cancer and its high expression in primary breast tumors is a significant predictor of subsequent metastasis and mortality (21). In a similar manner, increased HOTAIR expression may also indicate poor prognosis and promote metastasis in non-small cell lung cancer (25), epithelial ovarian cancer (27) and colon cancer (23).

In the current study, the expression level of HOTAIR in HCC tissues versus adjacent non-cancerous tissues was examined by quantitative RT-PCR, and its clinical implications were investigated. The results revealed that HOTAIR expression was at least 2 -fold higher in $60 \%$ of HCC samples, and the extent of the increase ranged from 2- to 46-fold (mean, 5.7-fold). With regard to clinicopathological significance, HOTAIR expression levels were closely associated with tumor differentiation $(\mathrm{P}=0.002)$, metastasis $(\mathrm{P}=0.002)$ and early recurrence $(\mathrm{P}=0.001)$. Furthermore, a Spearman's rank correlation coefficient analysis revealed that high HOTAIR expression was linked to poor tumor differentiation 
$(\mathrm{r}=0.391, \mathrm{P}=0.002)$ and advanced TNM stage $(\mathrm{r}=0.293$, $\mathrm{P}=0.023)$ and predicted a greater tendency for metastasis $(\mathrm{r}=0.408, \mathrm{P}=0.001)$ and early recurrence $(\mathrm{r}=0.433, \mathrm{P}=0.001)$. From these data, we hypothesize that HOTAIR participates in the development and progression of HCC. As certain clinicopathological characteristics, including tumor differentiation, TNM stage, metastasis and recurrence, always indicate poor prognosis, HOTAIR may be a predictor of poor prognosis in HCC patients, warranting further research.

Previous reports have suggested that HOTAIR may regulate cell proliferation, migration and invasion in a variety of tumor cell types (35-37). In endometrial carcinoma, the overexpression of HOTAIR increases the malignant potential of tumor cells in vitro and in vivo (24). The knockdown of HOTAIR lncRNA suppresses tumor invasion in gastric cancer cells and reverses the epithelial-mesenchymal transition (38). To explore the biological function of HOTAIR in HCC progression, a lentivirus-mediated shRNA expression system capable of interfering with HOTAIR expression in HepG 2 cells was developed in the present study. The data demonstrated that knockdown of HOTAIR significantly suppressed the proliferation and invasion of HepG 2 cells in vitro, and effectively reduced the oncogenicity of liver cancer cells HepG2 in vivo. Taken together, these data indicate that high levels of HOTAIR may promote the progression of liver cancer cells; this mechanism remains to be explored.

The Wnt/ $\beta$-catenin signaling pathway is a group of signal transduction pathways, which was first identified for its role in carcinogenesis and has been demonstrated to promote tumor development in multiple types of human cancer. Ge et al (39) found that HOTAIR is able to directly reduce the expression of Wnt inhibitory factor 1 , activating the $\mathrm{Wnt} / \beta$-catenin signaling pathway; this clarified one of the molecular mechanisms underlying progression and metastasis in esophageal squamous cell carcinoma, and may represent a novel therapeutic target in these patients (39). The present study examined the expression of Wnt and $\beta$-catenin in neoplasms of the nude mice from two groups. The results revealed that the mRNA expression level of Wnt and $\beta$-catenin were repressed when HOTAIR was silenced. Emerging evidence has demonstrated that the Wnt/ $\beta$-catenin signaling pathway plays a key role during HCC genesis and development, and may be a therapeutic target in human HCC $(40,41)$. We hypothesize that HOTAIR may influence carcinogenesis partially through activating and cooperating with the Wnt/ $\beta$-catenin signaling molecules in HCC. However, further research is necessary to clarify the exact mechanism of HOTAIR in HCC.

In conclusion, the present study demonstrated that HOTAIR expression is upregulated in the majority of HCC tissues, and is closely associated with tumor differentiation, metastasis and early recurrence in HCC patients. Furthermore, the overexpression of HOTAIR promotes HCC progression partly by activating the Wnt/ $\beta$-catenin signaling pathway. Thus, downregulating HOTAIR by interference may serve as a promising therapeutic strategy for the treatment of HCC.

\section{Acknowledgements}

The authors would like to thank their colleagues from the Department of Molecular Biology and the Department of
Gastroenterology of Chinese PLA General Hospital for their technical support.

\section{References}

1. El-Serag HB and Rudolph KL: Hepatocellular carcinoma: Epidemiology and molecular carcinogenesis.Gastroenterology 132: 2557-2576, 2007.

2. Bosch FX, Ribes J, Diaz M and Cléries R: Primary liver cancer: Worldwide incidence and trends. Gastroenterology 127 (5 Suppl 1): S5-S16, 2004.

3. Turdean S, Gurzu S, Turcu M, Voidazan S and Sin A: Current data in clinicopathological characteristics of primary hepatic tumors. Rom J Morphol Embryol 53 (Suppl 3): 719-724, 2012.

4. Severi T, van Malenstein H, Verslype C and van Pelt JF: Tumor initiation and progression in hepatocellular carcinoma: Risk factors, classification and therapeutic targets. Acta pharmacol Sin 31: 1409-1420, 2010.

5. Tang ZY: Hepatocellular carcinoma surgery-review of the past and prospects for the 21st century. J Surg Oncol 91: 95-96, 2005.

6. Qi LN, Bai T, Chen ZS, Wu FX, Chen YY, De Xiang B, Peng T, Han ZG and Li LQ: The p53 mutation spectrum in hepatocellular carcinoma from Guangxi, China: Role of chronic hepatitis $\mathrm{B}$ virus infection and aflatoxin B1 exposure. Liver Int 35: 999-1009, 2015.

7. Ye H, Zhang C, Wang BJ, Tan XH, Zhang WP, Teng Y and Yang X: Synergistic function of Kras mutation and $\mathrm{HBx}$ in initiation and progression of hepatocellular carcinoma in mice. Oncogene 33: 5133-5138, 2014

8. Li J, Gao JZ, Du JL and Wei LX: Prognostic and clinicopathological significance of glypican-3 overexpression in hepatocellular carcinoma: A meta-analysis. World J Gastroenterol 20: 6336-6344, 2014.

9. Sun Q, Wang R, Wang Y, et al: Notch1 is a potential therapeutic target for the treatment of human hepatitis B virus X protein-associated hepatocellular carcinoma. Oncol Rep 31: 933-939, 2014.

10. Zhang CH, Xu GL, Jia WD, Ge YS, Li JS, Ma JL and Ren WH: Prognostic significance of osteopontin in hepatocellular carcinoma: A meta-analysis. Int J Cancer 130: 2685-2692, 2012.

11. Xie L, Jiang $\mathrm{H}$ and Wu F: Role of Wnt/ $/$-catenin signaling pathway in promoting tumorigenesis of hepatocellular carcinoma. Nan Fang Yi Ke Da Xue Xue Bao 34: 913-917, 2014 (In Chinese).

12. Janku F, Kaseb AO, Tsimberidou AM, Wolff RA and Kurzrock R: Identification of novel therapeutic targets in the PI3K/AKT/mTOR pathway in hepatocellular carcinoma using targeted next generation sequencing. Oncotarget 5: 3012-3022, 2014.

13. Perkel JM: Visiting 'noncodarnia'. Biotechniques 54: 301, 303-304, 2013.

14. KapranovP,Cheng J,DikeS,Nix DA,DuttaguptaR, Willingham AT, Stadler PF, Hertel J, Hackermüller J, Hofacker IL, et al: RNA maps reveal new RNA classes and a possible function for pervasive transcription. Science 316: 1484-1488, 2007.

15. Hung T and Chang HY: Long noncoding RNA in genome regulation: Prospects and mechanisms. RNA Biol 7: 582-585, 2010.

16. Koerner MV, Pauler FM, Huang R and Barlow DP: The function of non-coding RNAs in genomic imprinting. Development 136: 1771-1783, 2009.

17. Costanzi C and Pehrson JR: Histone macroH2A1 is concentrated in the inactive $\mathrm{X}$ chromosome of female mammals. Nature 393: 599-601, 1998.

18. Fu X, Ravindranath L, Tran N, Petrovics G and Srivastava S: Regulation of apoptosis by a prostate-specific and prostate cancer-associated noncoding gene, PCGEM1. DNA Cell Biol 25: 135-141, 2006.

19. Reis EM, Nakaya HI, Louro R, Canavez FC, Flatschart AV, Almeida GT, Egidio CM, Paquola AC, Machado AA, Festa F, et al: Antisense intronic non-coding RNA levels correlate to the degree of tumor differentiation in prostate cancer. Oncogene 23: 6684-6692, 2004.

20. Rinn JL, Kertesz M, Wang JK, Squazzo SL, Xu X, Brugmann SA, Goodnough LH, Helms JA, Farnham PJ, Segal E and Chang HY: Functional demarcation of active and silent chromatin domains in human HOX loci by noncoding RNAs. Cell 129: 1311-1323, 2007.

21. Gupta RA, Shah N, Wang KC, Kim J, Horlings HM, Wong DJ, Tsai MC, Hung T, Argani P, Rinn JL, et al: Long non-coding RNA HOTAIR reprograms chromatin state to promote cancer metastasis. Nature 464: 1071-1076, 2010. 
22. Tsai MC, Manor O, Wan Y, Mosammaparast N, Wang JK, Lan F, Shi Y, Segal E and Chang HY: Long noncoding RNA as modular scaffold of histone modification complexes. Science 329: 689-693, 2010

23. Wu ZH, Wang XL, Tang HM, Jiang T, Chen J, Lu S, Qiu GQ, Peng ZH and Yan DW: Long non-coding RNA HOTAIR is a powerful predictor of metastasis and poor prognosis and is associated with epithelial-mesenchymal transition in colon cancer. Oncol Rep 32: 395-402, 2014.

24. Huang J, Ke P, Guo L, Wang W, Tan H, Liang Y and Yao S: Lentivirus-mediated RNA interference targeting the long noncoding RNA HOTAIR inhibits proliferation and invasion of endometrial carcinoma cells in vitro and in vivo. Int J Gynecol Cancer 24: 635-642, 2014

25. Liu XH, Liu ZL, Sun M, Liu J, Wang ZX and De W: The long non-coding RNA HOTAIR indicates a poor prognosis and promotes metastasis in non-small cell lung cancer. BMC Cancer 13: 464, 2013.

26. Kim K, Jutooru I, Chadalapaka G, Johnson G, Frank J, Burghardt R, Kim S and Safe S: HOTAIR is a negative prognostic factor and exhibits pro-oncogenic activity in pancreatic cancer. Oncogene 32: 1616-1625, 2013.

27. Qiu JJ, Lin YY, Ye LC, Ding JX, Feng WW, Jin HY, Zhang Y, Li Q and Hua KQ: Overexpression of long non-coding RNA HOTAIR predicts poor patient prognosis and promotes tumor metastasis in epithelial ovarian cancer. Gynecol Oncol 134: 121-128, 2014.

28. Livak KJ and Schmittgen TD: Analysis of relative gene expression data using real-time quantitative PCR and the 2(-Delta Delta C(T)) Method. Methods 25: 402-408, 2001.

29. Shao R, Bao S, Bai X, Blanchette C, Anderson RM, Dang T, Gishizky ML, Marks JR and Wang XF: Acquired expression of periostin by human breast cancers promotes tumor angiogenesis through up-regulation of vascular endothelial growth factor receptor 2 expression. Mol Cell Biol 24: 3992-4003, 2004.

30. Edge SB and Compton CC: The American Joint Committee on Cancer: The 7th edition of the AJCC cancer staging manual and the future of TNM. Ann Surg Oncol 17: 1471-1474, 2010.

31. Farazi PA and DePinho RA: Hepatocellular carcinoma pathogenesis: From genes to environment. Nat Rev Cancer 6: 674-687, 2006.
32. Hu TH, Wang CC, Huang CC, Chen CL, Hung $\mathrm{CH}$, Chen $\mathrm{CH}$, Wang JH, Lu SN, Lee CM, Changchien CS and Tai MH: Down-regulation of tumor suppressor gene PTEN, overexpression of $\mathrm{p} 53$, plus high proliferating cell nuclear antigen index predict poor patient outcome of hepatocellular carcinoma after resection. Oncol Rep 18: 1417-1426, 2007.

33. Niland CN, Merry CR and Khalil AM: Emerging roles for long non-coding RNAs in cancer and neurological disorders. Front Genet 3: 25, 2012.

34. Spizzo R, Almeida MI, Colombatti A and Calin GA: Long non-coding RNAs and cancer: A new frontier of translational research? Oncogene 31: 4577-4587, 2012.

35. Li X, Wu Z, Mei Q, Li X, Guo M, Fu X and Han W: Long non-coding RNA HOTAIR, a driver of malignancy, predicts negative prognosis and exhibits oncogenic activity in oesophageal squamous cell carcinoma. Br J Cancer 109: 22662278, 2013

36. Gupta RA, Shah N, Wang KC, et al: Long non-coding RNA HOTAIR reprograms chromatin state to promote cancer metastasis. Nature 464: 1071-1076, 2010

37. Geng YJ, Xie SL, Li Q, Ma J and Wang GY: Large intervening non-coding RNA HOTAIR is associated with hepatocellular carcinoma progression. J Int Med Res 39: 2119-2128, 2011.

38. Xu ZY, Yu QM, Du YA, Yang LT, Dong RZ, Huang L, Yu PF and Cheng XD: Knockdown of long non-coding RNA HOTAIR suppresses tumor invasion and reverses epithelial-mesenchymal transition in gastric cancer. Int J Biol Sci 9: 587-597, 2013.

39. Ge XS, Ma HJ, Zheng XH, Ruan HL, Liao XY, Xue WQ, Chen YB, Zhang Y and Jia WH: HOTAIR, a prognostic factor in esophageal squamous cell carcinoma, inhibits WIF-1 expression and activates Wnt pathway. Cancer Sci 104: 1675-1682, 2013.

40. Qu B, Liu BR, Du YJ, Chen J, Cheng YQ, Xu W and Wang XH: $\mathrm{Wnt} / \beta$-catenin signaling pathway may regulate the expression of angiogenic growth factors in hepatocellular carcinoma. Oncol Lett 7: 1175-1178, 2014

41. Dahmani R, Just PA and Perret C: The Wnt/ $/$-catenin pathway as a therapeutic target in human hepatocellular carcinoma. Clin Res Hepatol Gastroenterol 35: 709-713, 2011. 